\title{
Comparison of Tramadol with Combination of Tramadol and Ketorolac for Post Cesarean Section Analgesia
}

\author{
Regmi $\mathrm{NK}^{1}$, Jahan $\mathrm{K}^{2}$, Rai $\mathrm{P}^{2}$, Bhandari $\mathrm{A}^{2}$
}

\section{ABSTRACT}

Introduction: Effective post-operative analgesia is mandatory following cesarean section (CS), as parturients need to recover quickly to breast feed and provide care for their newborns. Till date no single drug has been able to achieve this goal. Multimodal analgesia with opioids and non-steroidal anti-inflammatory drugs (NSAID) combination has shown promising results. Aim: To compare the analgesic efficacy, patient satisfaction and maternal adverse effects, between intravenous (IV) tramadol and multimodal analgesia with IV tramadol and IV ketorolac combination for post cesarean section analgesia. Methods: This is a prospective, randomized and single-blinded comparative study, conducted in 60 parturients who underwent Lower Segment Cesarian Section. They were divided into two groups: Group 1 (IV Tramadol 50 mg given 8 hourly) and Group 2 (IV Tramadol 50 mg + IV Ketorolac 30 mg given 8 hourly). IV Promethazine was given with each dose of tramadol in both groups. Results: The (Visual analogue scale) VAS scores were significantly low in IV tramadol + IV ketrolac group than with IV tramadol alone group at 2 hours and 12 hours with $p$ value of 0.003 and 0.08 respectively. Rescue analgesia was significantly reduced in group 2 ( $p$ value 0.005 ). Patient satisfaction was good in group 2 and fair in group 1(p value 0.002). No maternal side effects were found. Conclusions: IV tramadol and IV ketorolac combination used for post cesarean section analgesia significantly decreases post-operative pain, need of rescue analgesia and significantly increases patient satisfaction in comparison to IV tramadol alone.

\section{Keywords: Analgesia, Caesarean section, Ketorolac, Post-operative, Tramadol}

Authors:

1. Dr. Nabin Kumar Regmi

2. Dr. Kamar Jahan

3. Dr. Purnima Rai

4. Dr. Ankur Bhandari

${ }^{1}$ Department of Anesthesia, Nepalgunj Medical College and Teaching Hospital, Nepalgunj, Banke

2 Department of Obstetrics and Gynecology, Nepalgunj Medical College and Teaching Hospital, Nepalgunj, Banke

\section{Address for Correspondence:}

\author{
Dr. Nabin Kumar Regmi \\ Department of Anesthesia \\ Nepalgunj Medical College and Teaching Hospital \\ Nepalgunj, Banke, Nepal \\ Email: nabinkums@gmail.com
}

\section{INTRODUCTION}

Rate of Cesarean section is rising globally. As stated by Lancet, the global cesarean section rate was $21 \%$ in 2015. In Nepal it was $9 \%$ in $2016 .{ }^{1}$ Adequate post-operative analgesia in the cesarean section patients is crucial as they have different surgical recovery needs which include breastfeeding and care of the newborn. These can be impaired if analgesia is unsatisfactory. ${ }^{2}$ Yet there is no any "gold standard" analgesic for post CS pain management. ${ }^{3}$ Multimodal and preventive approach to provide postoperative analgesia is gaining popularity these days ${ }^{4}$. NSAIDs and acetaminophen are commonly added to a postcaesarean analgesic regimen along with opioid medications to improve post-caesarean pain relief and reduce opioid requirements. ${ }^{5}$ Tramadol, a centrally acting analgesic provides analgesia via multimodal mechanism involving the $\mu$-opioid agonism, the noradrenergic and serotonergic reuptake inhibition at descending inhibitory pain pathway. It has been shown to provide effective analgesia for post-operative pain. However, for severe postoperative pain, the use of tramadol as the sole analgesic is not recommended. ${ }^{6,7}$ Ketorolac is the NSAID of choice for post-cesarean section analgesia and has been used to control post-operative pain in immediate postpartum period in women for whom multi modal analgesia is indicated. ${ }^{8,9}$ Solo tramadol, ketorolac and occasionally their combinations have been used in our institution for years. Limited studies exist in the literatures that compare the effects of tramadol alone with tramadol and ketorolac combinations as analgesic agents post-CS. So, in this study we tried to compare tramadol with tramadol and ketorolac combination taking pain intensity, rescue analgesia and patient satisfaction 
needed as our primary outcomes whereas pruritus, respiratory depression, nausea and vomiting as our secondary outcomes.

\section{METHODS}

This is a prospective, randomized and single blinded comparative study. This study was conducted from Jan. 2020 to June 2020, in the department of anesthesiology, Nepalgunj Medical College, after taking approval from Institutional Review Committee. 60 parturient between the ages of 18 and 50 years, with an ASA grade I and II undergoing lower segment cesarean section under spinal anesthesia with plain $0.5 \%$ bupivacaine were enrolled, after taking written consent. No intrathecal opioids were administered. Patient with cardiac disease, asthma, bleeding disorders, peptic ulcer disease, renal injury/failure and hypersensitivity to any of the study drugs were excluded from the study. Patient on anti-platelets, anticoagulants, antipyretics, antidepressant, antipsychotics and MgSO4 were also excluded.

In post-operative room parturients were divided into two groups randomly: Group 1 who received IV tramadol $50 \mathrm{mg}$ 8 hourly and Group 2 who received IV tramadol 50 mg + IV ketorolac $30 \mathrm{mg} 8$ hourly. The analgesics were started as soon as the parturients were brought to post-operative room, as per randomization. IV Promethazine $25 \mathrm{mg}$ diluted in $9 \mathrm{ml}$ normal saline (Total Volume $10 \mathrm{ml}$ ) was given slowly over 5 minutes following each dose of tramadol in both the groups to counteract pruritus, nausea and vomiting that can be caused by tramadol. Pain intensity, rescue analgesia and patient satisfaction needed were our primary measures whereas pruritus, respiratory depression, nausea and vomiting were our secondary measures. Postoperative pain intensity was measured using a $10 \mathrm{~cm}$ Visual Analogue Scale labeled ' $0=$ no pain' to ' $10=$ worst pain imaginable' at $2,6,12,18$ and 24 hours following surgery. IM Diclofenac $75 \mathrm{mg}$ was given as rescue analgesia at the request of the patients. The number of patients requiring rescue analgesia as well as the time it was taken was recorded. At the end of the 24 hours period, overall rating of satisfaction with quality of analgesia was done with 5 points Likert Scale. Very poor, poor, fair, good, and excellent patient satisfaction were considered as points 1, 2, 3, 4 and 5 respectively in this scale. ${ }^{10}$

Pruritus, respiratory depression, nausea and vomiting were noted.

\section{STATISTICAL ANALYSIS}

Data was analyzed using SPSS 20. Two sample $T$ test and chi square test were used. $P$ value and $X^{2}$ asymp. Sign. Value less than 0.005 were considered significant in $T$ test and chi square test respectively.

\section{RESULTS}

There were total 60 patients in the study. The mean age in group 1 was $25.67 \pm 5.248$ and in group 2 26.23.There was no significant difference in age between the two study groups. (Table I)

\begin{tabular}{|cccccc|}
\hline Variables & Group & N & Mean & Std. Deviation & P value \\
\hline Age (Years) & Group 1 & 30 & 25.67 & 5.248 & .669 \\
& Group 2 & 30 & 26.23 & 4.953 & \\
\hline
\end{tabular}

Table I : Comparison of age between the groups

VAS Score was significantly less in group 2 at 2 hours and 12 hours postoperatively. (Table II, Figure 1)

\begin{tabular}{|llllll|}
\hline Variables & Groups & N & Mean & $\begin{array}{c}\text { Std. } \\
\text { Deviation }\end{array}$ & P value \\
\hline \multirow{2}{*}{ VAS Score 2 hours } & Group 1 & 30 & 3.03 & 1.189 & \\
& group 2 & 30 & 2.17 & 0.986 & 0.003 \\
\hline \multirow{2}{*}{ VAS Score 6 hours } & Group 1 & 30 & 2.53 & 1.167 & \\
& group 2 & 30 & 2.30 & 1.055 & 0.420 \\
\hline \multirow{2}{*}{ VAS Score 12 hours } & Group 1 & 30 & 2.53 & 1.167 & \\
\hline \multirow{2}{*}{ VAS score 18 hours } & group 2 & 30 & 1.83 & 0.747 & 0.008 \\
& Group 1 & 30 & 2.40 & 1.404 & \\
\hline \multirow{2}{*}{ VAS Score 24 hours } & group 2 & 30 & 2.20 & 0.484 & 0.466 \\
& group 1 & 30 & 1.83 & 0.592 & \\
& group 2 & 30 & 1.53 & 0.681 & 0.074 \\
\hline
\end{tabular}

Table II : Comparison of Pain Intensity (VAS Score) at different intervals

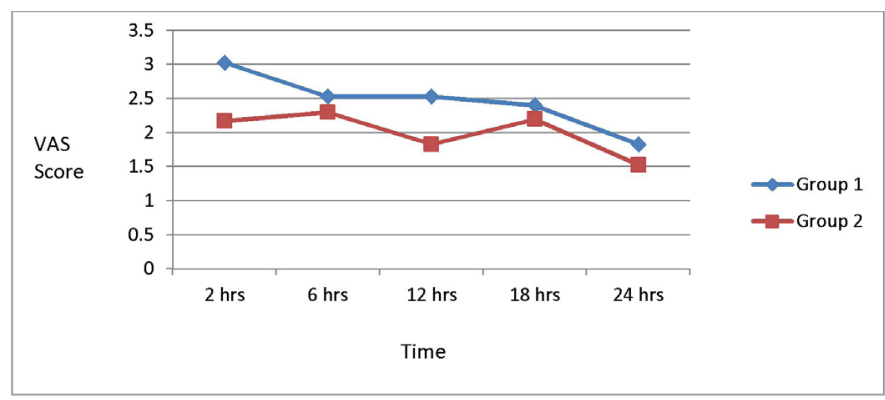

Figure 1 : Graph of mean VAS scores over 24 hours period

Requirement of rescue analgesia was significantly higher in group 1 in comparison to group 2. (Table III)

\begin{tabular}{|c|c|c|c|c|c|}
\hline Variables & & Group 1 & Group 2 & Total & P value \\
\hline \multirow{2}{*}{$\begin{array}{l}\text { Rescue Analgesia } \\
\text { (IM Diclofenac) }\end{array}$} & Not Given & $\begin{array}{c}16 \\
(53 \%)\end{array}$ & $\begin{array}{c}26 \\
(87 \%)\end{array}$ & 42 & \multirow{3}{*}{ 号 } \\
\hline & Given & $\begin{array}{c}14 \\
(47 \%)\end{array}$ & $\begin{array}{c}4 \\
(13 \%)\end{array}$ & 18 & \\
\hline Total & & 30 & 30 & 60 & \\
\hline
\end{tabular}

Table III : Comparison of requirement of Rescue Analgesia between the two groups 


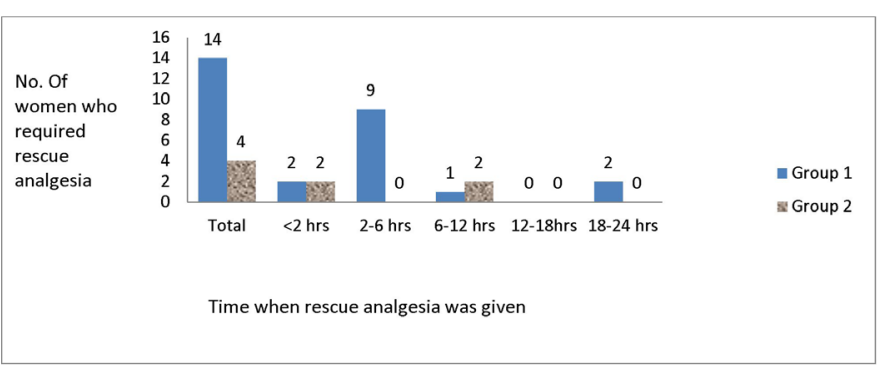

Figure 2 : Comparison of time for rescue analgesia given between the groups

No woman had likert scale score other than 3 (Fair) or 4 (Good). There was significant difference between fair and good satisfaction between the groups. (Table IV)

\begin{tabular}{|ccccc|}
\begin{tabular}{|ccc|c|} 
Overall pain Satisfaction taken at \\
24 hours (Likert Scale)
\end{tabular} & Group 1 & Group 2 & Total $\begin{array}{c}\text { P } \\
\text { value }\end{array}$ \\
\hline Likert Scale 3 & 19 & 7 & 26 & 0.002 \\
\hline Likert Scale 4 & 11 & 23 & 34 & \\
\hline \multicolumn{1}{|c|}{ Total } & 30 & 30 & 60 & \\
\hline
\end{tabular}

Table IV : Comparison of overall pain satisfaction level between the two groups

No parturients complained nausea and vomiting in both the groups. None had pruritus, and respiratory depression.

\section{DISCUSSION}

Effective pain relief after cesarean section is a global challenge as both maternal and neonatal adverse effects are to be considered. Effective pain relief after cesarean section improves a woman's ability to function, breast feed and interact with her newborn infant. It increases maternal satisfaction, decreases maternal morbidity and hospital stay. ${ }^{11}$ Post-cesarean pain consists of a somatic and visceral component. Visceral pain originates from uterine incision and contractions whereas the somatic component arises from the abdominal wall incision. It is unlikely that a single analgesic or targeted agent will significantly reduce most visceral pains since multiple neurotransmitters, channels, and receptors are responsible for visceral pain. Analgesics combinations are anticipated to be better than single analgesics..$^{12}$ Opioids are still playing a central role in post cesarean section pain management. However, from all published data, it is clear that opioids alone do not completely relieve pain after cesarean section. ${ }^{13} \mathrm{To}$ overcome this many centers around the world, combine opioid with non-opioid analgesics. ${ }^{3}$ Tramadol being an atypical opioid, has very low risk of respiratory depression, pruritus and abusive potential compared to the classical opioids. ${ }^{6}$ Tramadol with its relative infant dose of $2.4-2.9$, has no reports of toxicity in breast fed infants after maternal use. ${ }^{9,12}$ On top of that tramadol has a potency which is equal to pethidine and $1 / 10$ of morphine. ${ }^{14}$ NSAIDs should be given routinely in the immediate postpartum period, unless contraindicated. Among the nonsteroidal anti-inflammatory drugs investigated, ketorolac is safe in immediate post-partum breast feeding woman with relative infant dose 0.2 to 0.4 . It has an analgesic efficacy similar to opioids. ${ }^{9,11}$ IV Ketorolac produces opioid sparing effect by approximately $30 \%-45 \% .15,16$

In our study, VAS score was significantly decreased in ketorolac and tramadol group in 2 and 12 hours. Similar to our study, Lowder JL et al in their study found that ketorolac combined with opioids significantly decreases the VAS score in the first post-operative day of cesarean section in comparison to opioids and placebo. ${ }^{17}$ The difference in VAS score was not significant at 6,18 and 24 hrs. This insignificance at 6 hours could be because 9 parturients i.e. $64 \%$ of rescue analgesia receivers of group 1 received rescue analgesia between 2 to 6 hours. At 12 to 24 hours the intensity of pain might have decreased resulting in no significant difference in VAS. Our study shows multimodal analgesia with ketorolac and tramadol provides significant patient satisfaction ( $P$ value 0.002 ) than tramadol alone. A similar study done by Adamou $\mathrm{N}$ et al. found that multimodal analgesia with diclofenac and pentazocine provides statistically significant patient satisfaction ( $P$-value 0.00001 ) than pentazocine alone in early post cesarean section pain control. ${ }^{3}$

Thippeswamy $\mathrm{T}$ et al. in their study found that, $35 \%$ women in tramadol only group required rescue analgesia in first 24 hours postoperatively ${ }^{7}$, similarly $47 \%$ women of our tramadol only group required rescue analgesia which was significantly greater than $13 \%$ women in tramadol plus ketorolac group.

Despite the main side effect of tramadol being nausea and vomiting, there was no incidence of nausea and vomiting in our study. This result is similar to the result of study done by Shankariah $\mathrm{M}$, where they used intraoperative antiemetics. ${ }^{18}$ (Shankariah M), but is in contrast to result of Mitra $S$ et al, where no prophylactic antiemetics were used and tramadol resulted in nausea and vomiting in 15\% of parturients. ${ }^{5}$

Likewise pruritus not found in our study could be due to addition of promethazine with tramadol.

Respiratory depression was not found in any woman. Study done by Houmes RJ supports this result where $50 \mathrm{mg}$ tramadol given 8 hourly, did not cause respiratory depression in any parturients. ${ }^{19}$

\section{LIMITATION}

Comparison of our study with the similar study was limited in the discussion, as only few studies exist in the literatures that compare tramadol with combination of tramadol and ketorolac as analgesic agents post-CS.

\section{CONCLUSION}

IV Tramadol and IV ketorolac combination used for post cesarean section analgesia significantly decreases post-operative pain, need of rescue analgesia and significantly increases patient satisfaction in comparison to IV tramadol alone. 
Regmi et al.: Comparison of Tramadol with Combination of Tramadol and Ketorolac for Post Cesarean Section Analgesia

\section{REFRENCES}

1. Rai SD, Regmi PR, Teijlingen EV et al. Rising Rates of Caesarean Section in Urban Nepal. J Nepal Health Res Counc 2018 OctDec;16(41):479-80.doi: 10.33314/jnhrc.v16i41.1750.

2. Kerai S, Saxena KN, and Taneja B. Post-caesarean analgesia: What is new? Indian J Anaesth. 2017 Mar; 61(3): 200-214.doi: 10.4103/ija.IJA_313_16.

3. Adamou N, Tukur J, Muhammad Z, Galadanci H. A randomised controlled trial of opioid only versus combined opioid and nonsteroidal anti inflammatory analgesics for pain relief in the first 48 hours after Caesarean section. Niger Med J. 2014 Sep;55(5) 369-373.doi:10.4103/0300-1652.140319.

4. Kumari UR, Zutshi V, Patel M, Marwah S. Analgesic efficacy of intravenous paracetamol versus intravenous tramadol after caesarean section: a single blind randomized controlled study. Int J Reprod Contracept Obstet Gynecol 2016 Dec;5(12):4285-9.

5. Mitra S, Khandelwal P, Sehgal A. Diclofenac-tramadol vs. diclofenacacetaminophen combinations for pain relief after caesarean section. Acta Anaesthesiol Scand. 2012 Jul;56(6):706-11.

6. Cao X, Zhang X. Comparison of different sufentanil-tramadol combinations for pain relief within the first 24 hours after cesarean section: a retrospective study. J Pain Res. 2018 Oct; 11: 2445-2451.doi: 10.2147/JPR.S177500.

7. Thippeswamy T, Krishnaswamy B, Bengalorkar GM, Mariyappa N.Comparison of Efficacy and Safety of Intramuscular Piroxicam and Tramadol for Post-operative Pain in Patients Undergoing Caesarean Delivery. J Clin Diagn Res. 2016 Nov;10(11):FC01FC04.doi:10.7860/JCDR/2016/21861/8785.

8. Fidkowski CW, Shah S, Kataria S, Alsaden MR (2018) A Randomized Controlled Trial of Intravenous and Intramuscular Ketorolac for Post-Cesarean Analgesia. J Anesth Clin Res 9: 861. doi:10.4172/2155-6148.1000861.

9. Committee opinion no 742. Post partum pain management. ACOG. 2018 Jul;132(1):e35-43.Washington, DC.

10. McLeod, S. A. Likert scale. Simply psychology. 2019 Aug. https:// www.simplypsychology.org/likert-scale.html

11. S Aghamir, M Mojtahedzadeh, F Alizadeh, H Khalili, M Sadeghi, A Najafi, K Rezaie, F Rafizadeh, FShabani. Propacetamol Vs. Tramadol For Post-Operative Pain Management After Urologic Surgery. The Internet Journal of Pharmacology. 2005 Volume 4 Number 2.

12. Sutton $C D$, Carvalho B. Optimal pain management after cesarean delivery. Anesthesiology Clin. Mar 01. 2017(35):1:https://doi. org/10.1016/j.anclin.2016.09.010

13. Davis MP. Drug management of visceral pain: concepts from basic research. Pain Res Treat. 2012;2012:265605. doi:10.1155/2012/265605.

14. Verstraete $S$, Van de Velde M. Post-cesarean section analgesia. Acta Anaesth. Belg. 2012;63(4):147-167.

15. Pavy TJ, Paech MJ, Evans SF. The effect of intravenous ketorolac on opioid requirement and pain after cesarean delivery. Anesth Analg. 2001;92(4):1010-1014. doi:10.1097/00000539200104000-00038.
16. Wong JO, Tan TD, Cheu NW, Wang YR, Liao CH, Chuang FH, et al. Comparison of the efficacy of parecoxib versus ketorolac combined with morphine on patient-controlled analgesia for post-cesarean delivery pain management. Acta Anaesthesiol Taiwan. 2010 Dec;48(4):174-7.doi: 10.1016/j.aat.2010.09.001.

17. Lowder JL, Shackelford DP, Holbert D, Beste TM. A randomized, controlled trial to compare ketorolac tromethamine versus placebo after cesarean section to reduce pain and narcotic usage. Am J Obstet Gynecol. 2003;189(6):1559-1562. doi:10.1016/j. ajog.2003.08.014.

18. Shankariah M, Mishra M, Kamath RA. Tramadol versus ketorolac in the treatment of postoperative pain following maxillofacial surgery. J Maxillofac Oral Surg. 2012;11(3):264-270.doi:10.1007/ s12663-011-0321-y.

19. Houmes RJ, Voets MA, Verkaack A, Erdmann W and Lachmann B. Efficacy and safety of tramadol versus morphine for moderate and severe postoperative pain with special regard to respiratory depression. Anesth Analg 1992;74:510-14. 